\title{
Transcriptomic comparison of ovarian granulosa cells between adult sheep and prepubertal lambs
}

\author{
Hao Tian ${ }^{1 \dagger}$, Panyu Ren ${ }^{1 \dagger}$, Kailing Liu', Chunjuan Qiu², Lihong Fan², Junlong Li² and Jian Hou ${ }^{1 *}$ (])
}

\begin{abstract}
Background: The oocyte development ability of prepubertal animals is significantly lower than that of adult animals. Granulosa cells (GCs) have an important function on regulation of follicular and oocyte development. Therefore, analysis of GC characteristics can be used to explore the developmental mechanism of follicles and oocytes.

Results: In order to understand the possible reasons for the differences in follicle and oocyte development between lambs and adult sheep, we utilized high-throughput sequencing technique to analyze the transcriptome of GCs from follicle-stimulating hormone (FSH) superstimulated adult ewes and prepubertal lambs. Adult ewes were treated with FSH for 3 days (group A) and lambs were FSH-treated for 2 days (group B) or 3 days (group C). Transcriptome analysis of GCs showed that there were 405 and 159 differentially expressed genes from A vs. B and A vs. C, respectively. The results indicated that prolonging the FSH-treatment of lambs made the GC state of lambs more similar to the adult ewes, but there were still a large number of differentially expressed genes between adult ewes and lambs. Further analysis showed that many differently expressed genes were implicated in cell proliferation and apoptosis, oocyte development and follicular ovulation. Cellular examination demonstrated that fatty acid binding protein 4 (FABP4), which was highly expressed in lamb GCs, had a potential of promoting cell apoptosis. Cytoplasmic phospholipase A2 (PLA2G4A), which was expressed lowly in lamb GCs, may be responsible for reduced synthesis of prostaglandins in cells and impaired follicle/oocyte development. In contrast, glutathione S-transferase $\beta-1$ (GSTT2B) and forkhead boxO6 (FOXO6) had no apparent effect on the proliferation and apoptosis of GCs.

Conclusions: Our study found dramatic transcriptomic differences in GCs between lambs and adult sheep, which may explain the possible reasons for the defects of follicle and oocyte development in lambs compared to adult sheep. Our data provides important information for further understanding the mechanism of follicular development in prepubertal animals and improving their oocyte developmental competence.
\end{abstract}

Keywords: RNA-seq, Transcriptome, Granulosa cells, Sheep, Prepubertal lamb

*Correspondence: houjian@cau.edu.cn

${ }^{\dagger}$ Hao Tian and Panyu Ren contributed equally to this work.

1 State Key Laboratory of Agrobiotechnology and College of Biological

Science, China Agricultural University, Beijing, China

Full list of author information is available at the end of the article

\section{Background}

The technology of in vitro embryo production with juvenile animals as oocyte donors, so called juvenile in vitro embryo transfer (JIVET), has a great application prospect in livestock breeding [1]. However, the embryonic development ability of oocytes from prepubertal animals is quite low and thus limits the application of JIVET technology in large scale $[2,3]$. In sheep, gonadotrophin treatment of prepubertal lambs can stimulate a great 
number of follicles to grow up to medium sizes $(2-4 \mathrm{~mm}$ in diameter) at oocyte aspiration, but the derived oocytes are always not competent during subsequent development in vitro when used in JIVET program $[4,5]$. The reasons for poor development of prepubertal oocytes are not fully understood and remains to be investigated.

In vivo, the oocytes grow and develop in follicles and suboptimal follicular environment may compromise the oocyte competence. Within an antral follicle, the oocyte is exposed to follicular fluid (FF) and enclosed by surrounding granulosa cells (GCs). GCs exert very important roles on oocyte development through secretion of factors into FF or direct communication with oocytes via gap junctions [6, 7]. Thus, the activity of GCs is correlated with oocyte developmental potential.

Recently, transcriptomic and proteomic analysis of GCs found that hundreds of genes or proteins were differentially expressed between adult ewes and juvenile lambs $[8,9]$. Proteomic profiling identified lots of proteins differentially abundant in lamb FF compared to adult ewes [10]. Transcriptional analysis of whole ovaries revealed that the expression patterns of miRNAs and mRNAs were quite different between adults and lambs [11]. Similarly in bovine, prepubertal heifers and adult cows had distinct properties of follicular environment and many genes that influence follicular functions and oocyte development were differently expressed in GCs between heifers and cows $[12,13]$. These studies suggest that the functional insufficiency of prepubertal follicular environment may explain the reduced oocyte quality of prepubertal animals. However, previous studies have not strictly correlated the developmental ability of oocytes with the gene expression of GCs. In addition, the possible functions of identified genes need to be tested in cells.

To further understand the mechanism of prepubertal follicle development, in the present study we compared the transcriptome of GCs between lambs and adults under the same superovulation regime and validated the effects of some differently expressed genes. Based on the data, we indicate that FSH-treatment of lambs for 3 days is more favorable to follicle and oocyte development than treatment for 2 days, but there are still significant differences in GC function between lambs and adult ewes.

\section{Results \\ Development ability of adult and lamb oocytes}

Table 1 shows the efficiency of oocyte harvest and embryo production from adult and prepubertal lamb donors. After FSH-treatment, the average number of oocytes recovered in the two lamb groups was much higher than that of adult ewes. After in vitro maturation and fertilization, there was no significant difference in cleavage rate between lambs and adults, but the blastocyst rate in the adult group was significantly higher than that of both lamb groups. There was no significant difference in the cleavage rate between the two lamb groups, but the blastocyst rate in the 3-day FSH-treatment group was significantly higher than that in the 2-day FSH-treatment group $(p<0.05)$.

\section{Global gene expression}

The transcriptome of ovine GCs was analyzed by global RNA sequencing of each sample. After filtered out lowquality reads and removed the adaptor sequences, we finally obtained $98.36-99.4 \%$ clean data in each sample (Supplemental Table S1). As shown in Fig. 1, we calculated the rate of all reads from each sample mapped onto the genome, and showed that $73.30 \%-77.95 \%$ of the reads were uniquely mapped onto the ovine genome (https:// www.ncbi.nlm.nih.gov/genome/?term=Ovis\%20Aries). These data were used to analysis of gene expression.

\section{Differentially expressed genes (DEGs)}

Differentially expressed genes between groups were identified using criteria including $\mathrm{q}$-value $\leq 0.01$ and $|\log 2 \mathrm{FC}|>1$. The expression profiles of DEGs are shown in Fig. 2A and B and detailed in supplementary Table S2. We found 405 DEGs between adult ewes

Table 1 Developmental competence of adult and lamb oocytes

\begin{tabular}{llllll}
\hline Groups & No. of donors & $\begin{array}{l}\text { No. of recovered } \\
\text { oocytes }\end{array}$ & $\begin{array}{l}\text { Average no. of oocytes } \\
\text { recovered } \\
\text { from each donor }\end{array}$ & $\begin{array}{l}\text { No. of cleaved } \\
\text { (Mean } \pm \text { SEM, \%) }\end{array}$ & $\begin{array}{l}\text { No. of blastocysts } \\
\text { (Mean } \pm \text { SEM, \%) }\end{array}$ \\
\hline Adult & 100 & 1202 & 12.2 & $823(68.4 \pm 4.9)$ & $83 / 199(40.5 \pm 1.9)^{\mathrm{a}}$ \\
Lamb-2D & 5 & 635 & 127 & $489(76.2 \pm 3.5)$ & $59 / 363(17.8 \pm 1.4)^{\mathrm{b}}$ \\
Lamb-3D & 5 & 560 & 112 & $450(78.2 \pm 9.1)$ & $67 / 255(27.9 \pm 3.1)^{\mathrm{c}}$ \\
\hline
\end{tabular}

Percentage of cleaved: No. of cleaved /No. of recovered oocytes

Percentage of blastocysts: No. of blastocysts/No. of cleaved. Only parts of embryos were cultured for evaluation of their development

Values with different letters ( $\mathrm{a}, \mathrm{b}$ and $\mathrm{c}$ ) within the same column are significantly different $(p<0.05)$

Adult Adult ewes were treated with FSH for 3 days, Lamb-2D Lambs were FSH-treated for 2 days, Lamb-3D lambs were FSH-treated for 3 days 


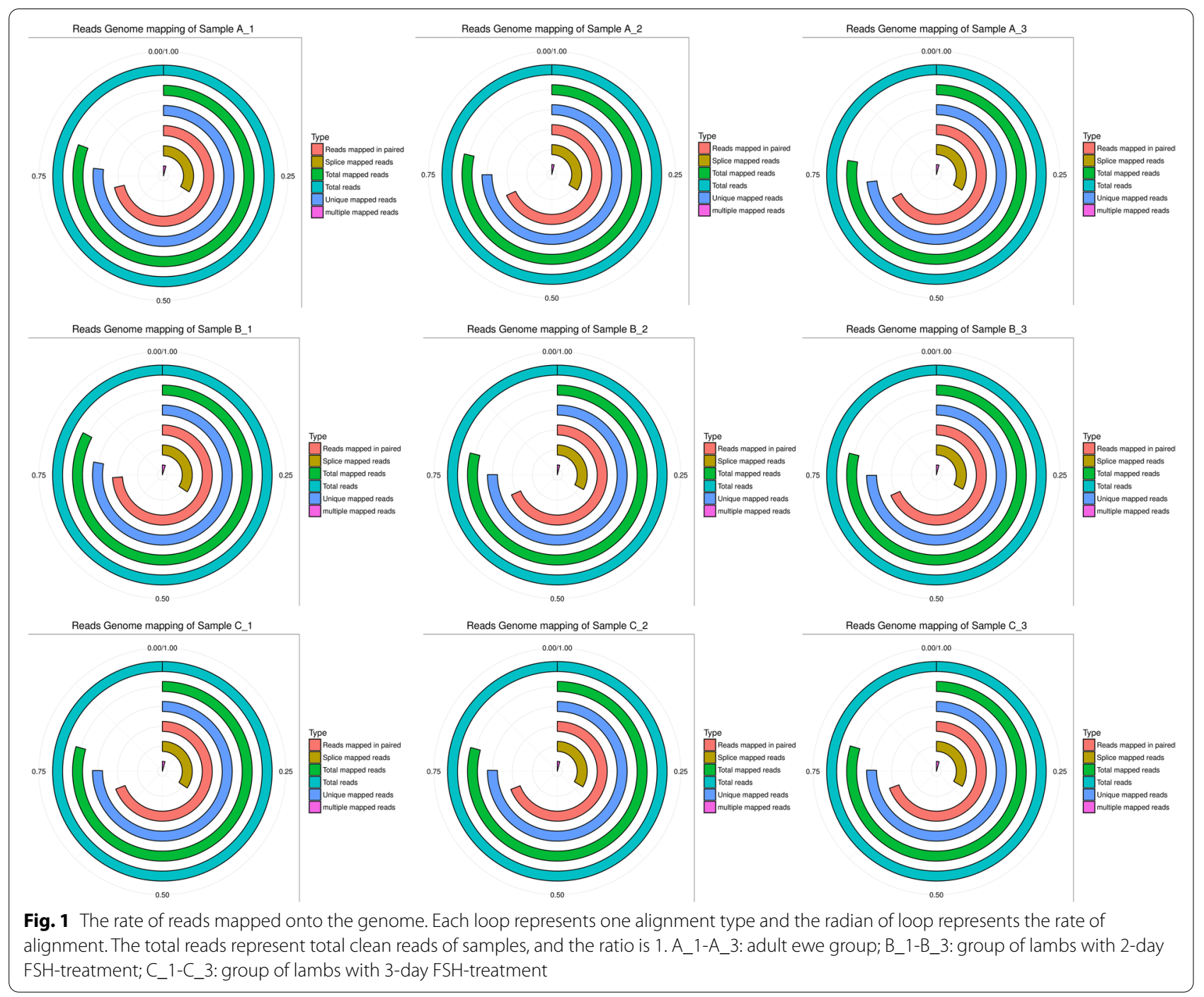

(A) and lambs with 2-day FSH-treatment (B) (referred to as A vs. B), and the number of up- and down-regulated genes was 190 and 215 in B group, respectively. There were 159 DEGs between adult ewes and lambs with 3-day FSH-treatment (C) (referred to as A vs. C), including 72 up- and 87 down-regulated genes in $\mathrm{C}$ group, respectively. For B vs. C, 28 DEGs were found, of which 12 were up-regulated and 16 were down-regulated in $C$ group. Overall, the number of DEGs from A vs. C was decreased by 246 compared to A vs. B.

We further explored the DEGs through pairwise comparative analysis of different groups and found 101 common DEGs existed in A vs. B \& A vs. C (Fig. $2 \mathrm{C}$ and supplementary Table S2). Among them, 53 genes were up-regulated and 48 genes were down-regulated in both lamb groups compared to adult group.

\section{Analysis of GO and KEGG pathways}

In order to further investigate the biological relevance of all DEGs, we performed GO analysis of DEGs to identify enrichment of biological processes in each group. The DEGs from A vs. B and A vs. C were enriched in many identical GO terms, but the enriched GO terms from A vs. B were more than A vs. C (2114 vs. 1178). The top $30 \mathrm{GO}$ terms of biological process (BP), cellular component (CC) and molecular function (MF) of A vs. B and A vs. C are shown in Fig. 3A. All DEGs were mapped to the KEGG database to further investigate their functions. A total of 405 DEGs from A vs. B were categorized into 231 pathways, and 159 DEGs from A vs. C were categorized into 181 pathways (q-value $\leq 0.05$ ). The representative top 20 pathways are shown in Fig. 3B. 


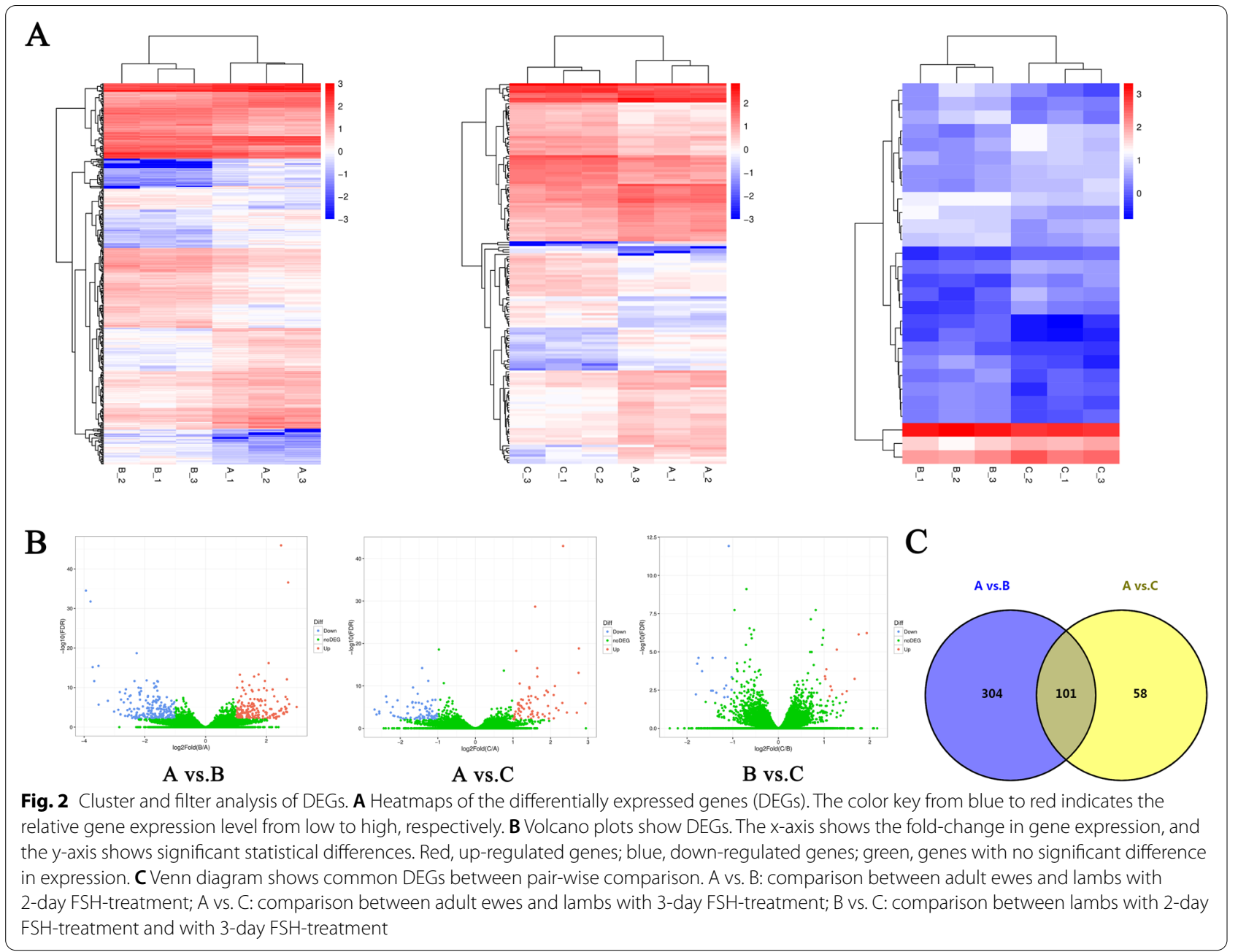

Next, we conducted GO and KEGG enrichment analysis for the common DEGs from A vs. B \& A vs. C. As shown in Table 2 and supplementary Table S3, the common DEGs were enriched in 767 GO terms, including 533 biological processes, 91 cell components and 143 molecular functions. A total of $16 \mathrm{GO}$ terms were enriched significantly $(p<0.05)$, including 9 biological processes (such as cell adhesion, extracellular matrix organization and regulation of cell proliferation), 5 cellular components (such as proteinaceous extracellular matrix, cell surface, and extracellular vesicular exosome), and 2 molecular functions (structural constituent of muscle and protein homodimerization activity). KEGG pathway analysis revealed that the common DEGs were enriched in 160 pathways and significantly enriched in 38 pathways, including adherens junction, regulation of lipolysis in adipocytes, ECM-receptor interaction, PI3K-Akt pathway, and protein digestion and absorption signaling pathway.

\section{Protein-Protein Interaction (PPI) network analysis}

When protein-protein interaction of the DEGs were analyzed, we found that the PPI network of $A$ vs. $B$ was reconstructed from 123 gene symbols (Figure 4A and supplementary Table S4). Biological function analysis on the gene symbols by clueGO revealed that the genes were related to endothelial cell migration, nephron development, carboxylic acid transport, fatty acid transport $(B P)$, contractile fiber part, collagen-containing extracellular matrix, actin-based cell projection (CC) and GABA-A receptor activity (MF) (Figure 4B). The genes were involved in TGFbeta signaling, cholinergic synapse and morphine addiction pathways. The PPI network of $A$ vs. $C$ was reconstructed from 41 gene symbols (Figure 4A). The genes were related to complex of collagen trimers (CC), GABA-A receptor activity 


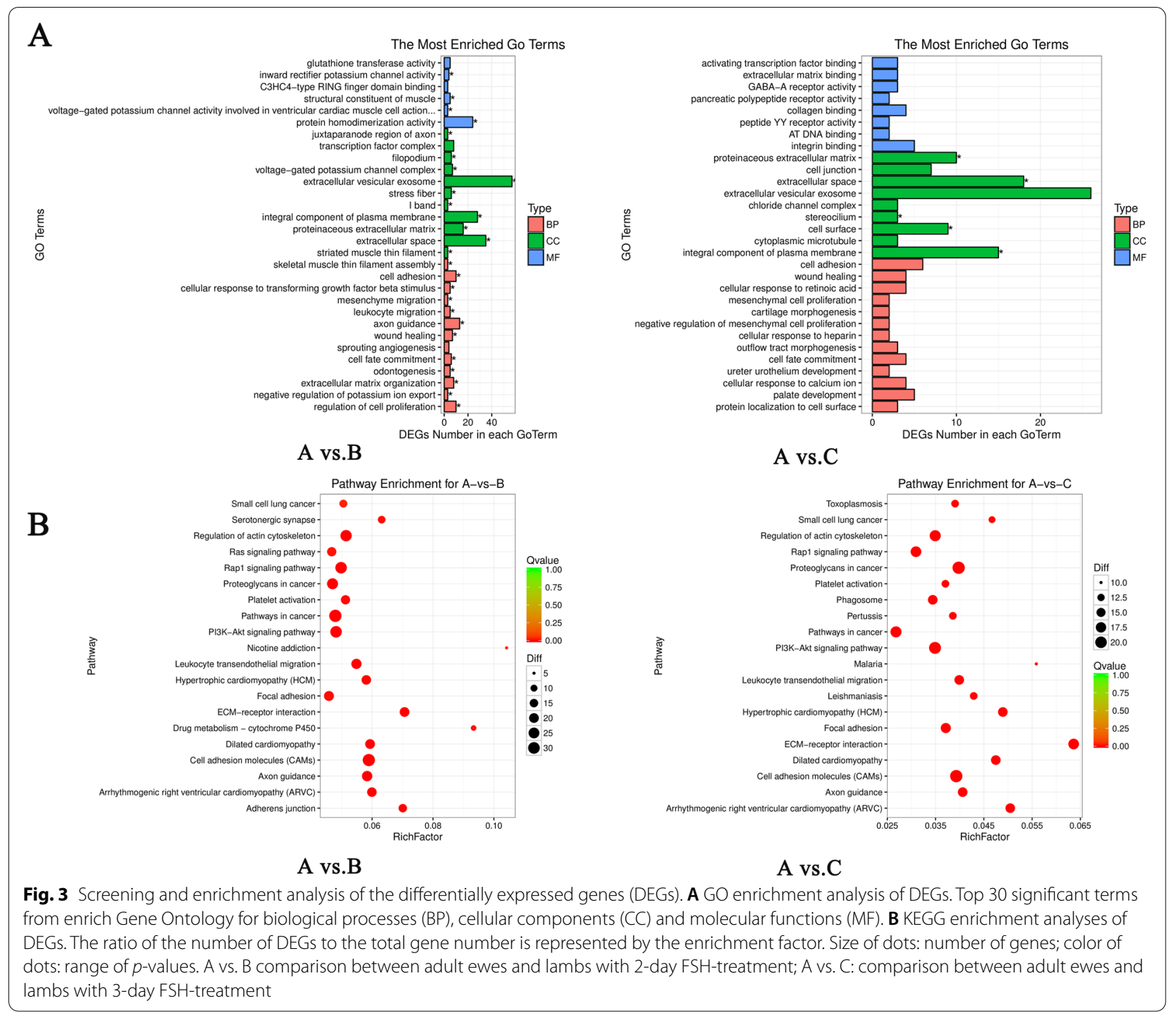

Table 2 GO/KEGG Enrichment analysis of differentially expressed genes among different comparisons

\begin{tabular}{ll}
\hline & $\begin{array}{l}\text { A vs. B \& A vs. C } \\
\text { Intersection }\end{array}$ \\
\hline Biological process & $533(9)$ \\
Cellular component & $91(5)$ \\
Molecular function & $143(2)$ \\
KEGG Pathway & $160(40)$ \\
\hline
\end{tabular}

The value in parenthesis is the significant enrichment number of differentially expressed genes with $p$-value $\leq 0.05$

and extracellular ligand-gated ion channel activity $(M F)$ (Figure 4C). The genes were involved in nicotine addiction GABAergic synapse and mor- phine addiction pathways. The PPI network of $A$ vs. $B$ \& $A$ vs. $C$ was reconstructed from 24 gene symbols (Figure 4A). The genes were related to GABA-A receptor activity (MF) and involved in nicotine addiction, GABAergic synapse and morphine addiction pathways (Figure 4D).

\section{Validation of expression levels of DEGs}

Nineteen genes associated with follicle development, oocyte maturation and ovulation were selected for expression verification by qRT-PCR. The results showed that the trend of up- and down-regulation of gene expression was consistent with the RNA-seq, and the expression was significantly different between adult and lamb GCs (Fig. 5A and B), proving that our data of highthroughput RNA-seq were reliable. 

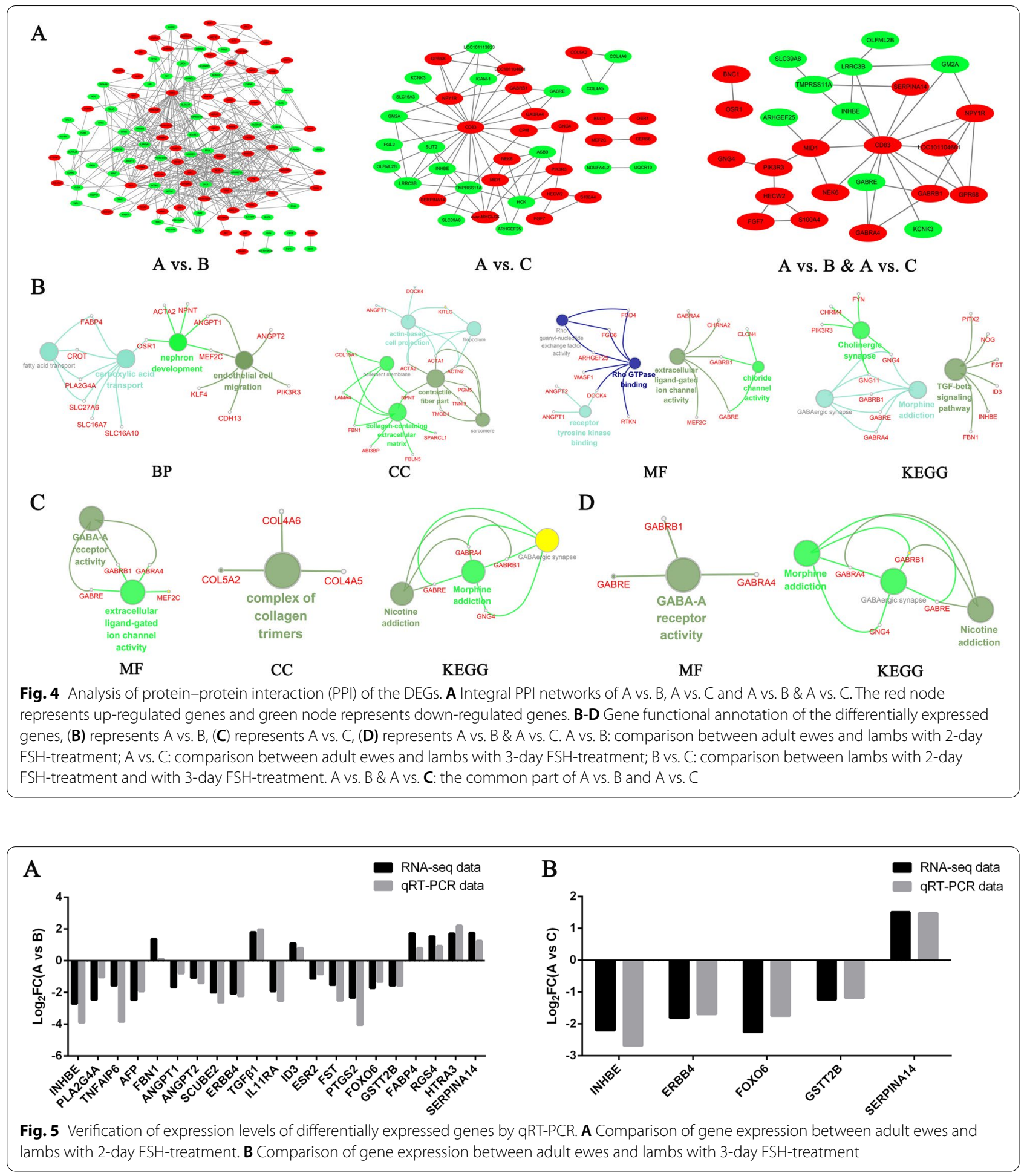

\section{Functional verification of some genes}

To further investigate the cellular function of genes, four genes including FABP4, PLA2G4A, FOXO6 and $G S T T 2 B$, were selected for functional examination in cells. We transfected overexpression vectors of these genes into adult GCs and achieved high expression of the target genes in cells (Fig. 6A-D). While, except for FOXO6, transfection of siRNAs could lead to significant decrease of expression of the target genes (Fig. 6a-d). 

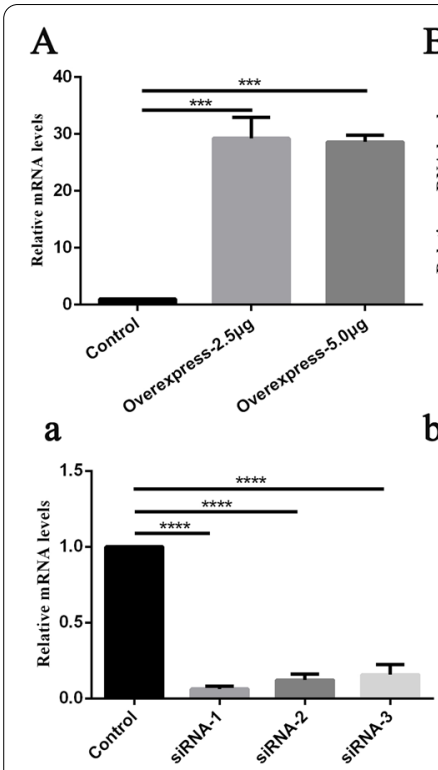
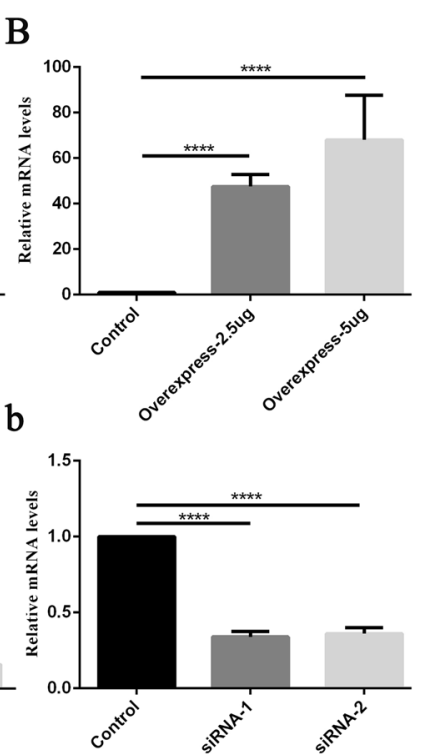
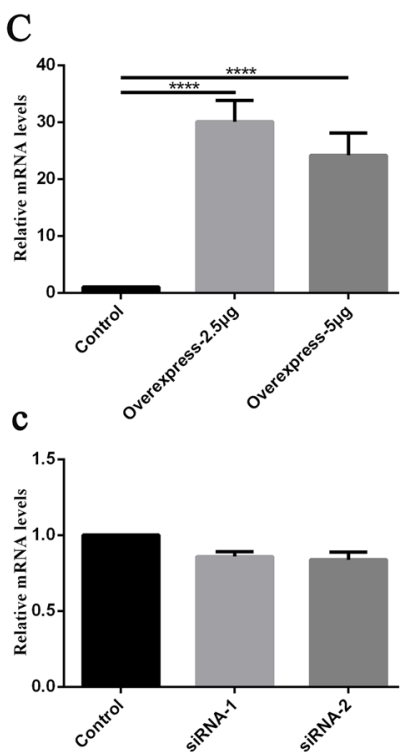

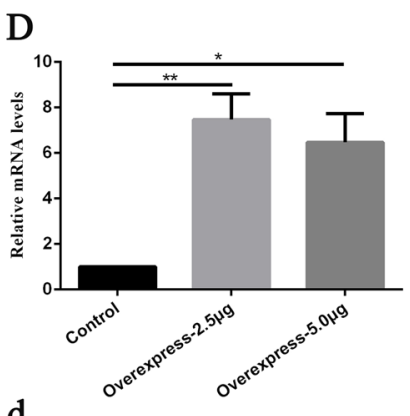

d

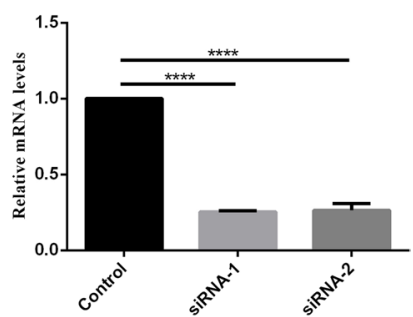

Fig. 6 The relative expression level of FABP4 (A, a), GSTT2B (B, b), FOXO6 (C, $\mathbf{c})$ and PLA2G4A (D, d) in transfected adult GCs. "Control" represents transfection with the empty plasmid; "Overexpress" represents transfection with overexpression vectors (transfected with 2.5 or $5.0 \mu \mathrm{g}$ of plasmids); "siRNA" represents transfection with siRNAs (the efficiency of 3 different siRNA were examined). The results are expressed as mean \pm SEM. ${ }^{*} p<0.05$, ${ }^{* *} p<0.01,{ }^{* * *} p<0.001,{ }^{* * * *} p<0.0001$

\section{The function of FABP4 in GCs}

The effect of FABP4 on proliferation and apoptosis of GCs from adult ewes was examined. Compared with the control group, the GC viability began to significantly decrease at $24 \mathrm{~h}$ after transfection with FABP4 overexpression vector, and the cell activity at 36,48 and $60 \mathrm{~h}$ after transfection was significantly lower than that of the control group (Fig. 7A). However, interference of $F A B P 4$ had no significant effect on the GC activity.

We then examined the expression of apoptosisrelated genes (BAX, BCL2 and Caspase3). We found that the relative expression levels of pro-apoptotic gene $B A X$ and Caspase 3 were significantly increased in FABP4 overexpressed GCs from adult ewes, while no significant changes were observed in the expression of anti-apoptotic gene BCL2. However, there were no significant differences in expression of BCL2, Caspase 3 and $B A X$ between the interference and control groups (Fig. 7B). TUNEL assay showed that the proportion of TUNEL-positive GCs was increased in the overexpression group, while the apoptotic ratio was decreased in the interference group (Fig. 7C).

\section{The function of PLA2G4A in GCs}

PLA2G4A is a cytosolic phospholipase that can promote the production of arachidonic acid (AA), a substrate of prostaglandin synthesis. We measured the level of arachidonic acid in culture medium of GCs, and found that the AA concentration in medium of lamb GCs was significantly lower than that of adult GCs (Fig. 8A).

Overexpression of PLA2G4A in adult GCs significantly increased the content of AA in the medium and interference of PLA2G4A decreased the AA level. In lamb GCs (Fig. 8B), overexpression of PLA2G4A also resulted in a significant increase of AA levels (Fig. 8C).

\section{The function of GSTT2B in GCs}

The effects of GSTT2B on antioxidation, proliferation and apoptosis of GCs were investigated. The results showed that the expression levels of antioxidant genes $S O D 1, S O D 2, C A T$ and GPX1 did not change significantly after GSTT2B overexpression in either adult (Fig. 9C) or lamb GCs (Fig. 9c). The expression of GPX1 was significantly decreased in the interference group (Fig. 9C), while no obvious changes were observed in the expression of SOD1, SOD2 and CAT (Fig. 9C and c). We further found that overexpression or interference of GSTT2B had no significant effect on the ROS levels (Fig. 9B and b), cell viability (Fig. 9A and a) and apoptosis (Fig. 9D and d) in both adult and lamb GCs.

\section{The function of FOXO6 in GCs}

FOXO6 is related to regulation of cell apoptosis and the expression of FOXO6 was significantly lower in lamb compared to adult GCs. We found that, however, overexpression of FOXO6 in lamb GCs had no significant 


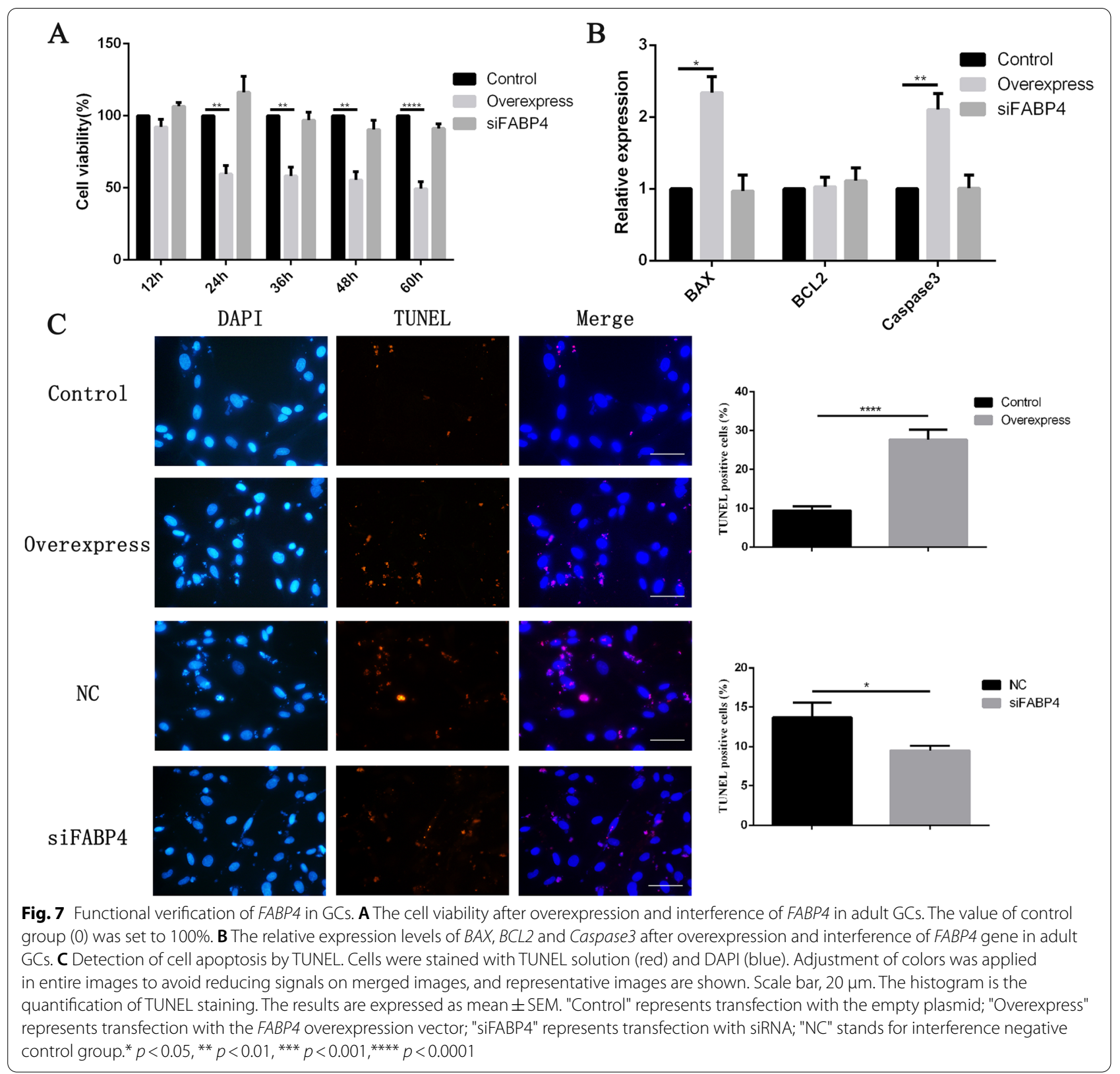

influence on cell viability, cell apoptosis and the relative expression levels of $B A X, B C L 2$ and Caspase 3 in cells (Fig. 10A-C). As the siRNAs tested were not efficient for knockdown of FOXO6 expression, the interference experiment was not done in the study.

\section{Discussion}

Low in vitro developmental ability of prepubertal oocytes suggests that the oocytes undergo insufficient development during growth in vivo. In the sheep JIVET program, the lambs are usually treated with injection of FSH for 2 days prior to oocyte recovery $[5,14]$. In this study, we showed that FSH-treatment for 3 days significantly enhanced the development of lamb oocytes when compared to FSH-treatment for 2 days, although it was still not comparable to adult oocytes from the same treatment protocol. Thus, increasing FSH-treatment and extending the in vivo development duration of prepubertal oocytes would be favorable to the improvement of oocyte competence. 

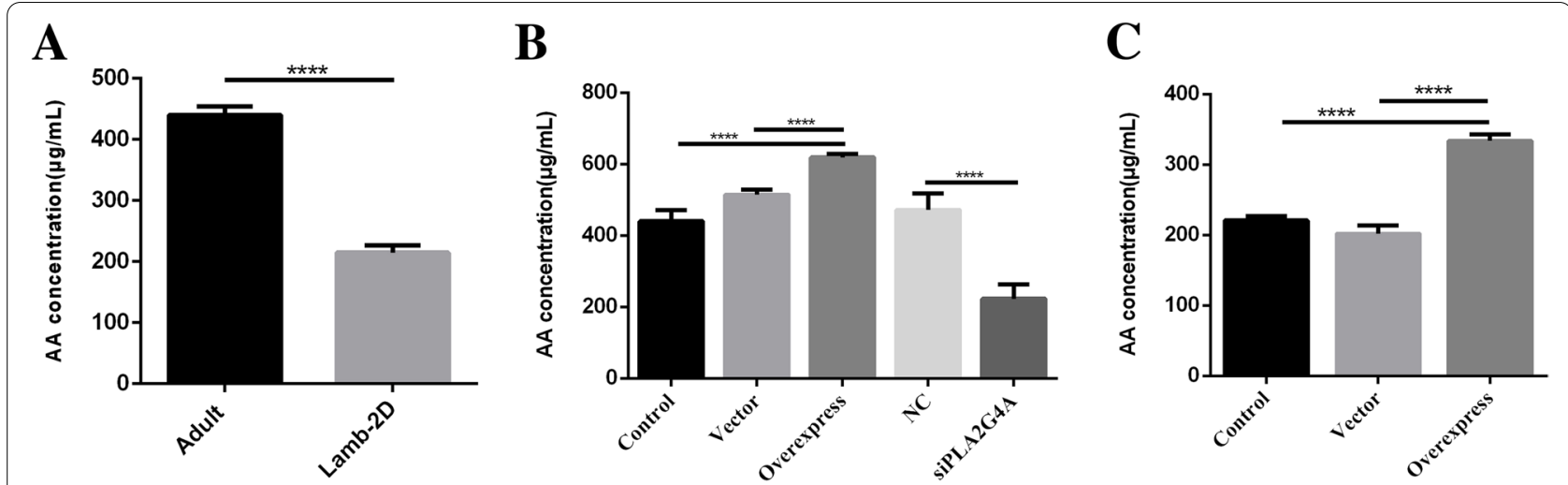

Fig. 8 Functional verification of PLA2G4A in GCs. The concentration of arachidonic acid (AA) in cell culture medium was measured using a detection kit. A The ability of GCs to secrete AA. "Adult" represents GCs from adult ewes, and "Lamb-2D" represents GCs from lambs with 2-day FSH-treatment. B Effects of overexpression or interference of PLA2G4A in adult GCs on secretion of AA. C Effects of overexpression of PLA2G4A in lamb GCs on secretion of AA. "Control" represents the untreated cells; "Vector" represents the cells transfected with the empty plasmid, pIRES2-ZsGreen 1;"Overexpress" represents the cells transfected with the PLA2G4A overexpression vector. "NC" stands for interference negative control group;"siPLA2G4A" represents transfection with siRNA. *** $p<0.0001$

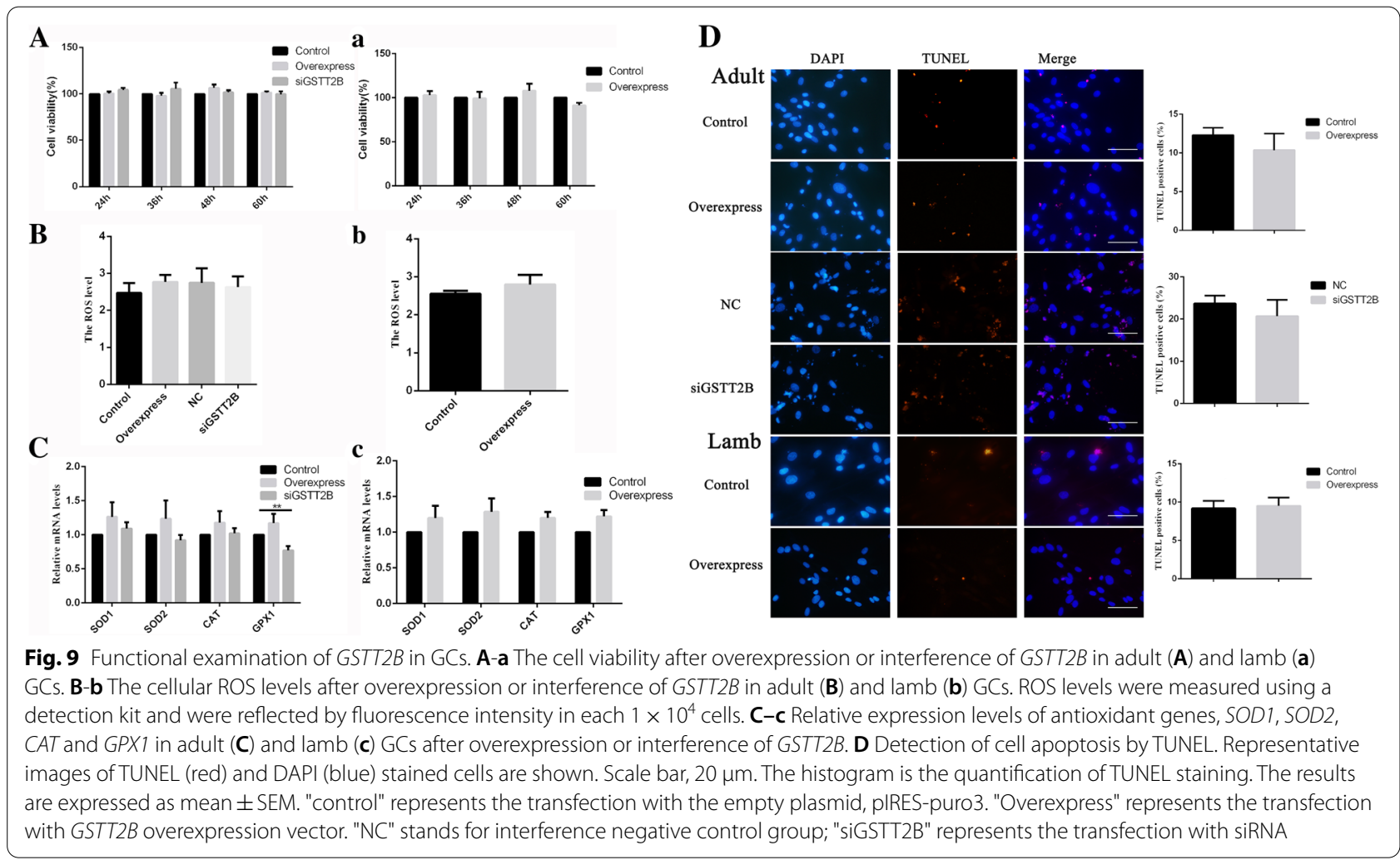

It is well known that there is a bidirectional communication between GCs and oocytes during development in follicles [6, 7]. GCs can coordinate the nuclear and cytoplasmic maturation of oocytes [15] and affect the growth and development of follicles [16]. Therefore, analysis of GC characteristics can be used to evaluate the quality of follicles and oocytes.
In this study, we used transcriptomic analysis to investigate the possible functions of GCs in FSH-treated lambs and found dramatic differences in gene expression patterns between lamb and adult GCs. Especially, a total of 405 DEGs were found in lambs with 2-day FSH-treatment vs. adult ewes, which is similar to a previous report 


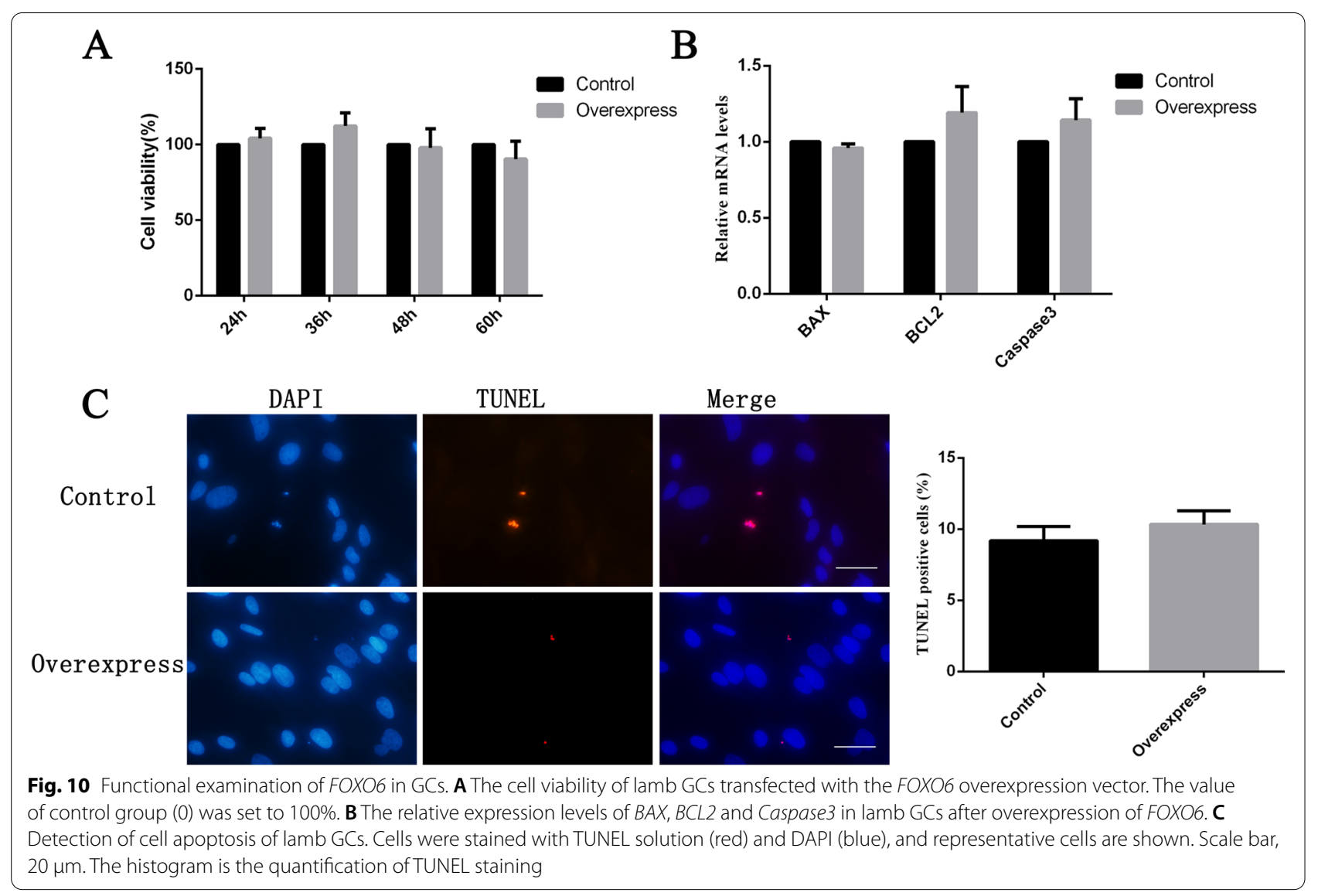

claiming 311 DEGs between lamb and adult GCs [9]. However, the number of DEGs decreased to 159 in lambs with 3-day FSH-treatment vs. adult ewes. The numbers of significantly enriched (q-value $\leq 0.05)$ GO terms and pathways from A vs. C were significantly less than that of A vs. B, which indicated that lengthening FSH treatment time probably made the follicular pattern of lambs more similar to adult ewes. Thus, compared to FSH treatment for 2 days, lambs with FSH-treatment for 3 days had been probably improved on some biological functions, such as cellular response to transforming growth factor beta stimulus, regulation of cell proliferation and extracellular vesicular exosome, etc.

We further investigated the DEGs by pairwise comparative analysis of the three groups and found 101 common DEGs shared with both 2-day and 3-day FSHtreatment of lambs vs. adults. These DEGs may represent the intrinsic differences between GCs of lamb and adult sheep, regardless of extending FSH-treatment to 3 days. Analysis of KEGG pathway combined with GO terms indicated that these common DEGs were enriched in biological processes such as cell adhesion, extracellular matrix organization, regulation of cell proliferation and so on. These DEGs were significantly enriched in some pathways including adherens junction, ECM-receptor interaction, cell adhesion molecules and PI3K-Akt pathway and so on. Among them, adherens junction (AJs) is the most common type of intercellular adhesion, which is pivotal for maintaining tissue structure and cell polarity, and can restrict the movement and proliferation of cells [17]. Cell adhesion molecule (CAMs) is a glycoprotein expressed on the cell surface, which plays an important role in a series of biological processes, including hemostasis, immune response, inflammation, embryonic development and neuronal tissue development [18, 19]. In ECM-receptor interaction signaling pathway, extracellular matrix is composed of complex mixtures of structural and functional macromolecules, including glycoproteins, proteoglycans, aminoglycans and so on. It plays a major role in the morphogenesis of tissues and organs and in maintaining the structure and function of cells and tissues [20]. The interaction between cells and extracellular matrix leads to direct or indirect control of cellular activities, such as adhesion, migration, differentiation, proliferation and apoptosis [21]. In addition, extracellular matrix is also involved in the process of cumulus expansion and plays a role in oocyte maturation [22]. PI3K-Akt signal transduction pathway is activated 
by Akt phosphorylation and participated in the regulation of basic cellular functions, such as the transcription, translation, proliferation and growth [23].

In order to further clarify the function mechanism of the differences in gene expression between lamb and adult GCs, we drew the PPI networks. The results showed that $C D 83$ was the core gene of three PPI networks. The expression of CD83 was up-regulated in lamb GCs. Previous studies have shown that CD83 is a member of the immunoglobulin (Ig) superfamily, which is elevated in the serum of patients with autoimmune disease and hematological malignancies and has an immune suppressive function [24]. In addition, Liu et al. proposed that ovulation involved the expression and function of molecules that exert potent roles in innate immune responses, and granulosa cells appeared to play immuno-protective-like functions for the ovulated oocytes [25]. Another report found that the possible initiation of early follicular atresia in small antral follicles during the follicular phase had an interaction with the presence of immune cells [26]. Our results suggest that up-regulation of CD83 in lamb GCs may have an adverse effect on the immune system and development of oocytes.

Enrichment of function analysis revealed same and different enrichment of GO terms between A vs. B and A vs. C. The candidate genes from PPI network of A vs. $B$ were enriched in endothelial cell migration, fatty acid transport, Rho GTPase binding and collagen-containing extracellular matrix, and so on. Rho GTPase binding is participated indirectly in oocyte maturation, blastocyst formation and stem cell development by regulated Rhoassociated coiled-coil-containing protein (ROCKs) [27]. Endothelial cell migration is essential for angiogenesis [28]. Angiogenesis is participated in the follicular development and ovulation [29], and thus there is a certain connection between the two. Extracellular matrix (ECM) constitutes the follicular basal lamina and is responsible for aggregation of granulosa cells, and it is vital for supporting ovarian follicle growth and maintaining its proper function [30]. In this study, we found some DEGs encoding ECM-related proteins in collagen-containing extracellular matrix (A vs. B) and complex of collagen trimmers (A vs. C), such as collagens COL15A1, FBN1 (A vs. B) and COL4A5, COL4A6, COL5A2 (A vs. C) [31]. Therefore, the enrichment of GO terms was related to the differences in follicular development and ovulation between lamb and adult ewes.

We verified the expression of 19 DEGs that are implicated in follicle and oocyte development by qRT-PCR. Inhibin B (INHBE, also known as activin E) is expressed in GCs of early antral follicles and dominant follicles, which promotes the development of single dominant follicle by inhibiting the secretion of pituitary FSH in follicular phase [32]. Follistatin (FST) is a binding protein of activins. The activin-follistatin system controls the growth and differentiation of antral follicles by affecting the production of gonadotropin receptors and steroids [33]. As a follicle develops to a dominant follicle, activin secretion is decreased, while inhibin and follistatin production are increased [34]. In our results, INHBE and FST were expressed lowly in lambs GCs, which may hinder the selection of dominant follicles and permit a large number of lamb antral follicles to grow in response to FSH stimulation.

$E R B B 4$ is one of the four receptors in mammalian EGFR system [35]. Studies have demonstrated that EGFlike factors and EGFR signaling pathway played vital roles in the regulation of oocyte meiosis resumption, the expansion of cumulus cells and ovulation [36, 37]. Prevot et al. found that there was a significant delay in puberty in $E R B B 4$ mutant mice, and their reproductive function was also impaired in adulthood [38]. In view of this, ERBB4 may play a certain role in the reproductive process, and its low expression in lamb GCs may not facilitate the activation of the EGFR signaling pathway, thus reflecting some developmental defects of lamb oocytes.

In agreement to a previous report [9], we found that HTRA3 was differently expressed between adult and lamb GCs. HTRA3 is a member of the HtrA family of serine proteases and plays an important role in ovarian development, GC differentiation and luteinization [39]. It was reported that the expression level of HTRA3 was significantly increased in luteinized GCs [40]. In this study, we found that the expression of HTRA3 in lamb GCs is significantly higher than that in adult GCs. This implies that lamb GCs may undergo luteinization, which is not favorable to the full development of follicles and oocytes.

ESR2, TGFB1, TNFAIP6, PTGS2 and AFP are related to ovulation. As a receptor of estrogen, ESR2 is critical for full development and maturation of follicles and oocytes [41]. TGF $\beta 1$ can induce PTGS2 expression and prostaglandin E2 (PGE2) production in GCs through Smad signaling pathway, which further promotes oocyte maturation and ovulation [42]. TNFAIP6 specifically expresses in mucilaginous liquefaction cumulus-oocyte complexes (COCs) [43], which is indispensable for the formation of extracellular matrix in COCs during ovulation [44]. Prostaglandin is involved in ovulation, and PTGS2 plays a key role in synthesis of prostaglandins [45]. AFP is a serum glycoprotein. Female mice with $A F P$ knockout were unable to ovulate due to hypothalamic dysfunction [46]. The expression of these genes was significantly lower in lamb GCs than adult GCs, which may be the reasons that lamb follicles rarely ovulate.

$F B N 1$ is a glycoprotein and is involved in regulating the activity of $T G F \beta$. When FBN1 is silenced, the 
proliferation of cumulus cells is significantly increased and the apoptosis of cumulus cells is prevented [47]. The high expression of $F B N 1$ in lamb GCs may inhibit the proliferation of GCs and affect the normal secretory and metabolic process of GCs.

$S C U B E 2$ is a new type of vascular growth factor receptor 2 co-receptor and can enhance the signal transduction induced by vascular endothelial growth factor (VEGF) during angiogenesis, thus promoting angiogenesis [48]. ANGPT1 and ANGPT2 are participated in maturation and stabilization of blood vessels via tyrosine kinase receptors $[49,50]$. ID3 is involved in the control of cell cycle and cell fate, and may also play an important role in angiogenesis [51]. Fraser et al. suggested that angiogenesis plays a critical role in follicular development, and interference with the process of angiogenesis can inhibit follicular development or prevent ovulation [52]. Low expression of ANGPT1, ANGPT2 and SCUBE2 in lamb GCs may hinder follicular maturation and ovulation by inhibiting follicular angiogenesis.

In this study, we examined the functions of four genes, FABP4, PLA2G4A, GSTT2B and FOXO6, in ovine GCs. $F A B P 4$ is expressed mainly in adipocytes and has been widely studied in obesity metabolic syndrome and cardiovascular disease [53]. Van et al. observed that the ultrastructural characteristics of apoptotic GCs in bovine ovary was similar to those of $F A B P 4$ positive cells [54]. High expression of FABP4 was observed in the GCs of atretic follicles in mice [55]. It was found that FABP4 is closely related to the occurrence of polycystic ovary syndrome [56]. In this study, we found that FABP4 was highly expressed in GCs of lambs and demonstrated that overexpression of $F A B P 4$ promoted the apoptosis of GCs. FABP4 may play its role through PPAR $\gamma$ signal pathway [55]. It is also suggested that the promotion of apoptosis by $F A B P 4$ may be related to the up-regulation of TNFAIP6 and down-regulation of TGF- $\alpha$ [57]. These may be the reasons that FABP4 promotes apoptosis, but other mechanisms may also exist and need to be further investigated.

PLA2G4A is a cytosolic phospholipase that can promote the production of arachidonic acid (AA), a substrate of prostaglandin synthesis [58]. Boruszewska et al. suggested that PGE2 could facilitate successful oocyte maturation and oocyte survival in the cow [59]. In this study, the expression of PLA2G4A in GCs of adult ewes and 3-day FSH-treated lambs were higher than that of 2-day FSH-treated lambs. Overexpression and RNAi experiments demonstrated that PLA2G4A had an important effect on the ability of GCs to secrete AA. AA is a substrate for the synthesis of prostaglandin E2 that regulates the cumulus cells expansion [60]. Thus, the defective development of oocytes and follicles in lambs may be partially due to the low concentration of prostaglandin E2, and prolonged FSH treatment of lambs would be beneficial to the PLA2G4A expression and prostaglandin E2 synthesis, thereby promoting the oocyte maturation and development. In addition, Sapieha et al. believed that AA, as an unsaturated fatty acid, promotes angiogenesis [61]. Therefore, the low concentration of prostaglandin E2 in lamb follicles may reduce the formation of mature blood vessels on follicles, and thereby affect the oocyte maturation and follicular ovulation.

GSTs are involved in glutathione-dependent oxidation resistance [62]. GSTT2B is a member of the GSTs family, but its function is little known. It may act as an antioxidant, promoting detoxification of reactive oxygen species (ROS). Our results suggested that GSTT2B was expressed lowly in lamb GCs. Therefore, we speculated that lamb GCs may have a lower antioxidant capacity related to GSTT2B deficiency. However, we found that overexpression of or interference with this gene in lamb and adult GCs, had no significant roles in antioxidation and apoptosis in cells.

FOXO factors are important regulators of cell cycle, apoptosis, DNA repair, antioxidant stress and cell lifespan $[63,64]$. FOXO6 is a member of the FOXO family and is a vital regulator of insulin or liver glucose metabolism [65]. Knockdown of FOXO6 in colorectal cancer cells inhibited the cell proliferation, migration, invasion and glycolysis [66]. So far, there is no report of FOXO6 in ovine GCs. Our study showed that the expression of FOXO6 was significantly decreased in GCs of lamb treated with FSH for 2 and 3 days. We thought that FOXO6 might be a critical gene in regard to the difference in GC functions between lambs and adult ewes, and it may be related to cell proliferation. However, FOXO6 had no effect on cell proliferation and apoptosis in our assays. The role of FOXO6 in GCs needs further investigation.

\section{Conclusions}

In this study, we show that there were notable differences in transcriptional patterns of GCs between lambs and adult ewes, and a number of differently expressed gene were identified between the two groups of females, which partially explains the possible reasons for the developmental defects in lamb follicles and oocytes. Although the real actions of these differently expressed genes need to be further investigated, two genes, FABP4 and PLA2G4A, have been shown to have a function in granulosa cells like apoptosis and arachidonic acid synthesis. Finally, we demonstrate that prolonging the FSH-treatment of lambs would be favorable to the GC functions and oocyte development. Our study provides important data for further understanding the mechanism of follicular development in prepubertal 
animals and improving their oocyte developmental competence.

\section{Materials and methods}

\section{Animals, hormonal treatment and sample collection}

The procedure of all animal experiments was in accordance with the animal care policies of China Agricultural University and was approved by the Animal Ethics Committee at the university. During handling of animals, all efforts were made to minimize the pain and suffering experience of animals.

Dorper breed female lambs and adult ewes with good health were provided by Inner Mongolia Sino Sheep Technology Co. Ltd and kept in a farm of this company located at Wulanhua town, Wulanchabu, Inner Mongolia, China $\left(41^{\circ} 33^{\prime} \mathrm{N}, 111^{\circ} 38^{\prime} \mathrm{E}\right)$. All animals, including lambs with their mothers, were house-fed under conventional management conditions. Hormonal treatment of animals and surgery collection of samples were performed in early autumn (average temperature was around $19.5^{\circ} \mathrm{C}$ ). A total of 12 experimental lambs (4-6 wk old) were randomly allocated to two treatment groups and each lamb received 180 IU follicle-stimulating hormone (FSH) (Sansheng Pharmaceutical, Ningbo, China) in total, including $4 \times 45$ IU (2-day group; $n=6$ ) or $6 \times 30$ IU (3-day group; $n=6$ ), given at approximately $12 \mathrm{~h}$ intervals. At the time of the first FSH injection, lambs were simultaneously injected with 400 IU equine chorionic gonadotropin (eCG; Sansheng). Adult ewes were also used as oocyte donors for embryo in vitro production (IVP) and this technology has been routinely applied in sheep breeding in the company, Inner Mongolia Sino Sheep Technology. In parallel with the experiments on lambs, a total of 100 adult ewes (3-4 y old) were used to IVP program during that period. Thus, samples from these ewes were collected for comparisons with lambs. The ewes were implemented an intravaginal CIDR (InterAg, New Zealand) at any days of the cycle and $12 \mathrm{~d}$ later they received $6 \times 30 \mathrm{IU}$ injection of FSH with an interval of $12 \mathrm{~h}$ for each injection. All animals were subjected to one cycle of hormonal treatment and used only once in the experiments.

Oocytes were recovered from lambs and ewes approximately $12 \mathrm{~h}$ after the last FSH injection as described previously [67]. The animals were induced to general anesthesia by intramuscular injection of anesthetic (Su-Mian-Xin II, Institute of Military Veterinary, Changchun, China; injection dosage: $5 \mu \mathrm{l} / \mathrm{kg}$ body weight) and ovaries were exposed by mid-ventral laparotomy by surgery. The animals were carefully monitored for a week after surgery, and then maintained under normal conditions. Follicles $\geq 2 \mathrm{~mm}$ in diameter on ovarian surface were punctured and aspirated using a $10 \mathrm{G}$ needle disposable syringe. The cumulus-oocyte complexes (COCs) were picked under a stereo microscope and used for in vitro maturation. The remaining GCs were collected and cultured in DMEM/F12 supplemented with $10 \%$ fetal bovine serum (FBS) for 2-3 d. When the cell cultures reached $80 \%$ of confluence, the cells were harvested and stored at $-80{ }^{\circ} \mathrm{C}$ until RNA extraction.

\section{Oocyte in vitro maturation (IVM) and fertilization (IVF)}

The procedure of oocyte IVM/IVF was same as described previously [67]. Briefly, COCs were cultured at $38.5 \mathrm{C}$ for $24 \mathrm{~h}$ in a humidified atmosphere of $5 \% \mathrm{CO}_{2}$ in TCM199 supplemented with $20 \%$ (v:v) estrous sheep serum (ESS), $10 \mu \mathrm{g} / \mathrm{mL}$ FSH (Folltropin-V; Bioniche Inc., Belleville, Ont., Canada), $10 \mu \mathrm{g} / \mathrm{mL} \mathrm{LH}$ (Bioniche Inc) and $1 \mu \mathrm{g} / \mathrm{mL}$ $17 \beta$-estradiol. After maturation, the oocytes were fertilized in vitro using frozen-thawed sperm and incubated in IVF medium, synthetic oviduct fluid (SOF) supplemented with $2 \%$ ESS. After $20 \mathrm{~h}$, the presumptive fertilized oocytes were cultured in SOF medium containing $8 \mathrm{mg} / \mathrm{mL}$ fatty acid-free bovine serum albumin, $1 \%$ (v:v) essential amino acids and 2\% (v:v) non-essential amino acids, at $38.5 \mathrm{C}$ in a humidified atmosphere of $5 \% \mathrm{CO}_{2}$, $7 \% \mathrm{O}_{2}$ and $88 \% \mathrm{~N}_{2}$. The cleavage of fertilized oocytes and blastocyst development of embryos were evaluated after $2 \mathrm{~d}$ and $7 \mathrm{~d}$ of culture, respectively. All embryos generated in the experiments, including 945 2-cell embryos and 209 blastocysts, were transferred into recipient ewes for producing offspring. The data on preimplantation development of embryos was presented in this study (detailed in Table 1).

\section{RNA-seq and identification of differentially expressed genes} For Illumina sequencing, total RNAs from GCs were extracted by Trizol Reagent (Tiangen, Beijing, China). The GC samples were from three groups of animals, including adult ewes (A), lambs with FSH-treatment for 2 days (B) and for 3 days (C). Each group consisted of 3 biological replicates and each replicate contained a mixed GC sample from 2 individual animals. The quality of total RNAs was assessed using Agilent 2100 Bioanalyzer (Agilent Technologies, Palo Alto, CA). After reverse transcription, cDNA libraries were constructed and sequenced by using Illumina $\mathrm{HiSeq}^{\mathrm{TM}}$ 2000. After nine sets of raw reads were obtained, the data were deposited by removing the contaminated, datper and low-quality reads, and all reads were uniquely mapped onto the ovine genome (https://www.ncbi.nlm.nih.gov/genome/?term= Ovis\%20Aries).

For RNA-seq analysis, we used the Python-based toolkit HTseq to efficiently and accurately mapped reads 
to genes, and finally used the FPKM (fragment per kilobases per million mapped reads) method to calculate the expression level of each gene. Comparisons of FPKM in three groups (A vs. B, A vs. C and B vs. C) were performed, and genes with $\mathrm{q}$-value $\leq 0.01$ and $|\log 2 \mathrm{FC}|>1$ were considered as significant differently expressed genes (DEGs) for subsequent analysis.

\section{Data analysis}

We used Gene Ontology (GO) enrichment terms for the functional categories of DEGs. GO has a total of three ontologies, which describe the molecular function of genes, cellular components and biological processes. Then GO enrichment analysis of differentially expressed transcripts was implemented using GO-seq software package. All DEGs were mapped to the Kyoto Encyclopedia of Genes and Genomes (KEGG) (http://www. genome.jp/kegg) to further investigate their functions. GO terms and KEGG pathway with corrected p-values less than 0.05 were considered significantly enriched. The data sets of protein-protein interactions (PPIs) were obtained from the online data-base STRING 11.0 (http:// www.string-db.org/) and by a PPI prediction method called domain-domain interaction (DDI) that is based on the conservatism of the domain. After getting the PPIs, we made full use of Cytoscape 3.8.2 to show the PPIs and utilized the Clue-GO to cluster the GO terms and KEGG pathways.

\section{Validation by quantitative reverse transcription PCR (qRT-PCR)}

Purified total RNA of GCs was used as a template for cDNA synthesis by using FastKing gDNA Dispelling RT SuperMix (Tiangen, China). The real-time quantitative PCR was performed using the SuperReal PreMix Plus (Tiangen) in an ABI PRISM 7500 System (Applied Biosystems, USA). The $2^{-\Delta \Delta C T}$ method was used to determine the gene expression level. All primers were designed using Primer 5.0 (supplementary Table S5). All samples were analyzed in triplicates and all experiments were repeated for three times at least.

\section{Overexpression and interference of target genes in GCs}

Coding sequences (CDS) of specific target genes were cloned from GC cDNAs. Accession number of the genes and designed primers are shown in supplementary Table S5. The CDS were constructed into eukaryotic expression vectors, pIRES2-ZsGreen1or pIRES-puro3 (Clontech, USA). The small interfering RNAs (siRNAs) targeting genes and their control siRNA (si-con) were designed and synthesized by Sangon Biotech (Shanghai, China).
The overexpression vectors or siRNAs were transfected into cultured GCs using Lipofectamine 3000 (Invitrogen, Carlsbad, CA) according to the manufacturer instructions.

\section{Assessment of cell viability}

The CCK- 8 assay was used to assess the viability of transfected cells. The cells were seeded in 96-well plates and incubated at $37{ }^{\circ} \mathrm{C}$. The indices of cell proliferation were measured using a CCK-8 kit (Beyotime Institute of Biotechnology, China) at $12,24,36,48$, and $60 \mathrm{~h}$ after transfection. Then $10 \mu \mathrm{L}$ CCK-8 solution was added into the well and incubated for $1 \mathrm{~h}$ at $37{ }^{\circ} \mathrm{C}$. The optical density was measured using a microplate analyzer and the reference wavelength was set at $650 \mathrm{~nm}$ and the detection wavelength was set at $450 \mathrm{~nm}$.

\section{TUNEL assays}

The TUNEL was used for detecting DNA breaks by using One Step TUNEL Apoptosis Assay Kit, red fluorescence (Beyotime). Cell slides from different experimental groups were fixed with $4 \%$ paraformaldehyde at room temperature for $30 \mathrm{~min}$ and then treated with $0.3 \%$ Triton X-100 in PBS for 5 min. After that, $50 \mu \mathrm{L}$ TUNEL assay solution was dripped to cell slides, and the slides were incubated at $37^{\circ} \mathrm{C}$ for $60 \mathrm{~min}$. After cells were counterstained with DAPI, the slides were observed under a Qlympus BX51 epifluorescence microscope equipped with a DP72 microscope digital camera (Olympus Corporation, Tokyo, Japan), and the fluorescent images were acquired with Image-Pro Plus 6.0 software (Media Cybemetics, MD, USA). Six fields were selected randomly from each coverslip for observation and more than 200 cells from each field were recorded. The exposure length for catching each type of fluorescence was kept constant. After subtracting the background of images, the intensities of fluorescence in cells were quantified using Image-J 1.45 software (National Institutes of Health, USA). Apoptosis ratio was calculated as the number of apoptotic cells / total cell numbers.

\section{Detection of arachidonic acid concentration}

Sheep arachidonic acid (AA) ELISA detection kit (Beijing Shijichuangxiang Biotechnology, Beijing, China) was used to detect the concentration of $\mathrm{AA}$ in the medium of GCs. The cell culture medium was collected by centrifuge at $1000 \mathrm{rpm}$ for $10 \mathrm{~min}$. Antibodies against AA $(100 \mu \mathrm{L})$ labeled with horseradish peroxidase (HRP) were added to holes of Elisa Plate contained standard sample and samples except the blank, and they were incubated at $37^{\circ} \mathrm{C}$ for $60 \mathrm{~min}$. Then, the liquid was removed and the 
substrate of A and B were added to the hole of Elisa Plate and incubated for $15 \mathrm{~min}$ in dark. Finally, the terminated solution was added to the hole, and optical density was determined immediately at $450 \mathrm{~nm}$ by using a microplate analyzer.

\section{Intracellular ROS measurement}

A reactive oxygen species detection kit (Beyotime) was used to detect the levels of ROS in GCs according to the instruction of manufacture. DCFH-DA was added to the cell culture dish and incubated at $37^{\circ} \mathrm{C}$ for $20 \mathrm{~min}$. Then the cells were harvested and the number of cells was counted by using the cell count plate. The fluorescence intensity from $1 \mathrm{ml}$ cell suspension was detected by using the fluorescence spectrophotometer, and the fluorescence intensity of each 10,000 cells was calculated.

\section{Statistical analysis}

Analysis of data were performed using SPSS 18.0 software. Homogeneity of variances was analyzed by Levene's test and normality of the data was tested using the Kolmogorov-Smirnov test. Student $t$-test or one-way ANOVA test with post hoc by least significance difference test (LSD) was used to analyze the data that were normally distributed, and Mann-Whitney $U$ test was used to analyze the data that were not normally distributed. All data are expressed as mean \pm standard error. The graphs, transcriptome map and PPI networks were drawn using GraphPad Prism 5.0 software, $\mathrm{R} \times 64$ 3.6.2 software package and Cytoscape 3.8.2, respectively.

\footnotetext{
Abbreviations

AA: Arachidonic acid; AFP: Alpha fetal albumin; ANGPT1: Angiopoietin 1; ANGPT2: Angiopoietin 2; BAX: BCL2 associated X, apoptosis regulator; BCL2: BCL2 apoptosis regulator; BP: Biological process; CAT: Catalase; CC: Cellular component; CD83: CD83 molecule; CDS: Coding sequences; COL4A5: Collagen type IV alpha 5 chain; COL4A6: Collagen type IV alpha 6 chain; COL5A2: Collagen type V alpha 2 chain; CL15A1: Collagen type XV alpha 1 chain; COCs: Cumulus-oocyte complexes; DDI: Domain-domain interaction; DEGs: Differently expressed genes; ECM: Extracellular matrix; ERBB4: Erb-b2 receptor tyrosine kinase 4; ESS: Estrous sheep serum; ESR2: Estrogen receptor 2; FABP4: Fatty acid binding protein 4; FBN1: Fibrillin 1; FF: Follicular fluid; FOXO6: Forkhead boxO6; FSH: Follicle-stimulating hormone; FPKM: Fragment per kilo-bases per million mapped reads; FST: Follistatin; GCs: Granulosa cells; GO: Gene Ontology; GPX1: Glutathione peroxidase 1; GSTT2B: Glutathione S-transferase $\beta$-1; KEGG: Kyoto Encyclopedia of Genes and Genomes; HTRA3: HRP: Horseradish peroxidase; HTRA3: HtrA serine peptidase 3; ID3: Inhibitor of DNA binding 3; INHBE: Inhibin $\beta$ E subunit; IVF: In vitro fertilization; IVM: In vitro maturation; JIVET: Juvenile in vitro embryo transfer; MF: Molecular function; PGE2: Prostaglandin E2; PLA2G4A: Cytoplasmic phospholipase A2; PPIs: Protein-protein interactions; PTGS2: Prostaglandin-endoperoxide synthase 2; ROCKs: Rhoassociated coiled-coil-containing protein; SCUBE2: Signal peptide-CUB-EGF domain protein 2; siRNAs: Small interfering RNAs; SOD1: Superoxide dismutase 1; SOD2: Superoxide dismutase 2; SOF: Synthetic oviduct fluid; TGF $\beta 1$ : Transforming growth factor $\beta$ 1; TNFAIP6: Tumor necrosis factor a inductive protein; VEGF: Vascular growth factor.
}

\section{Supplementary Information}

The online version contains supplementary material available at https://doi. org/10.1186/s12864-022-08379-x.

Additional file 1: Table S1. The results of original data filtering.

Additional file 2: Table S2. The gene expression of all samples and DEGs between groups.

Additional file 3: Table S3. Go and pathway enrichment of DEGs.

Additional file 4: Table S4. The data sets of protein-protein interactions.

Additional file 5: Table S5. Sequences for primers.

\section{Acknowledgements}

We thank the members of our lab and staffs in the farm for their assistance in the study.

\section{Authors' contributions}

$\mathrm{JH}$ conceived and supervised the study. HT performed most experiments with assistance from KL. HT and PR analyzed the data. CQ, LF and JL assisted in producing embryos and evaluating the embryonic development. TH and PR draft the manuscript. JH reviewed and revised the manuscript. All authors approved the final submission.

\section{Funding}

This research was funded by China Agriculture Research System, grant number CARS-39-04. The funding body played no role in the design of the study and collection, analysis, and interpretation of data and in writing the manuscript.

\section{Availability of data and materials}

The datasets generated during the current study are available in the NCBI Sequence Read Archive (SRA), http://www.ncbi.nlm.nih.gov/bioproject/PRJNA 753660 .

\section{Declarations}

Ethics approval and consent to participate.

The study was conducted according to the guidelines of the Declaration of Helsinki. The informed consent to use the animals in this research was obtained from Inner Mongolia Sino Sheep Technology Co. Ltd and the procedure was approved by the Ethics Committee for Animal Welfare at China Agricultural University (protocol code: AW20701202-3-1, date of approval: 10 June, 2017).

\section{Consent for publication.}

Not applicable.

\section{Competing interests}

The authors declare no conflict of interest.

\section{Author details}

${ }^{1}$ State Key Laboratory of Agrobiotechnology and College of Biological Science, China Agricultural University, Beijing, China. ${ }^{2}$ Inner Mongolia, Sino Sheep Breeding Co. Ltd, Wulanchabu, Inner Mongolia, China.

Received: 16 August 2021 Accepted: 9 February 2022

Published online: 21 February 2022

\section{References}

1. Armstrong DT, Kotaras PJ, Earl CR. Advances in production of embryos in vitro from juvenile and prepubertal oocytes from the calf and lamb. Reprod Fertil Dev. 1997;9:333-9. https://doi.org/10.1071/r96080.

2. Paramio MT, Izquierdo D. Current status of in vitro embryo production in sheep and goats. Reprod Domest Anim. 2014;49(Suppl 4):37-48. https:// doi.org/10.1111/rda.12334 
3. Ledda S, Bogliolo L, Calvia P, Leoni G, Naitana S. Meiotic progression and developmental competence of oocytes collected from juvenile and adult ewes. J Reprod Fertil. 1997;109:73-8. https://doi.org/10.1530/ jrf.0.1090073.

4. Reader KL, Cox NR, Stanton JA, Juengel JL. Mitochondria and vesicles differ between adult and prepubertal sheep oocytes during IVM. Reprod Fertil Dev. 2015;27:513-22. https://doi.org/10.1071/rd13359.

5. Gou KM, Guan H, Bai JH, Cui XH, Wu ZF, Yan FX, et al. Field evaluation of juvenile in vitro embryo transfer (JIVET) in sheep. Anim Reprod Sci. 2009;112:316-24. https://doi.org/10.1016/j.anireprosci.2008.05.008.

6. Eppig JJ. Oocyte control of ovarian follicular development and function in mammals. Reproduction. 2001;122:829-38. https://doi.org/10. 1530/rep.0.1220829.

7. Gilchrist RB, Ritter LJ, Armstrong DT. Oocyte-somatic cell interactions during follicle development in mammals. Anim Reprod Sci. 2004;8283:431-46. https://doi.org/10.1016/j.anireprosci.2004.05.017.

8. Lin J, Wu Y, Han B, Chen Y, Wang L, Li X, et al. iTRAQ-based proteomic profiling of granulosa cells from lamb and ewe after superstimulation. Theriogenology. 2017;101:99-108. https://doi.org/10.1016/j.theriogeno logy.2017.06.014.

9. Wu Y, Lin J, Li X, Han B, Wang L, Liu M, et al. Transcriptome profile of one-month-old lambs' granulosa cells after superstimulation. AsianAustralas J Anim Sci. 2017;30:20-33. https://doi.org/10.5713/ajas.15. 0999.

10. Wu Y, Lin J, Han B, Wang L, Chen Y, Liu M, et al. Proteomic profiling of follicle fluids after superstimulation in one-month-old lambs. Reprod Domest Anim. 2018;53:186-94. https://doi.org/10.1111/rda.13091.

11. Zhang X, Dong C, Yang J, Li Y, Feng J, Wang B, et al. The roles of the miRNAome and transcriptome in the ovine ovary reveal poor efficiency in juvenile superovulation. Animals. 2021;11(1):239. https://doi.org/10. 3390/ani11010239.

12. Michalovic L, Currin L, Gutierrez K, Bellefleur AM, Glanzner WG, de Macedo MP, et al. Granulosa cells of prepubertal cattle respond to gonadotropin signaling and upregulate genes that promote follicular growth and prevent cell apoptosis. Mol Reprod Dev. 2018;85:909-20. https://doi.org/10.1002/mrd.23066.

13. Warzych E, Pawlak P, Pszczola M, Cieslak A, Lechniak D. Prepubertal heifers versus cows-The differences in the follicular environment. Theriogenology. 2017;87:36-47. https://doi.org/10.1016/j.theriogenology. 2016.08.007.

14. Kelly JM, Kleemann DO, Walker SK. Enhanced efficiency in the production of offspring from 4- to 8-week-old lambs. Theriogenology. 2005;63:1876-90. https://doi.org/10.1016/j.theriogenology.2004.09. 010.

15. Carabatsos MJ, Sellitto C, Goodenough DA, Albertini DF. Oocyte-granulosa cell heterologous gap junctions are required for the coordination of nuclear and cytoplasmic meiotic competence. Dev Biol. 2000;226:167-79. https://doi.org/10.1006/dbio.2000.9863.

16. Thomas FH, Vanderhyden BC. Oocyte-granulosa cell interactions during mouse follicular development: regulation of kit ligand expression and its role in oocyte growth. Reprod Biol Endocrinol. 2006;4:8. https://doi.org/ 10.1186/1477-7827-4-19.

17. Beavon IR. The E-cadherin-catenin complex in tumour metastasis: structure, function and regulation. Eur J Cancer. 2000;36:1607-20. https://doi. org/10.1016/s0959-8049(00)00158-1.

18. Elangbam CS, Qualls CW Jr, Dahlgren RR. Cell adhesion moleculesupdate. Vet Pathol. 1997;34:61-73. https://doi.org/10.1177/0300985897 03400113.

19. Montoya MC, Sancho D, Vicente-Manzanares M, Sanchez-Madrid F. Cell adhesion and polarity during immune interactions. Immunol Rev. 2002;186:68-82. https://doi.org/10.1034/j.1600-065x.2002.18607.x.

20. Walker C, Mojares E, Del Río Hernández A. Role of extracellular matrix in development and cancer progression. Int J Mol Sci. 2018;19(10):3028. https://doi.org/10.3390/ijms19103028.

21. Bosman FT, Stamenkovic I. Functional structure and composition of the extracellular matrix. J Pathol. 2003;200:423-8. https://doi.org/10.1002/ path. 1437.

22. Chen X, Bonfiglio R, Banerji S, Jackson DG, Salustri A, Richter RP. Micromechanical analysis of the hyaluronan-rich matrix surrounding the oocyte reveals a uniquelysoft and elastic composition. Biophys J. 2016;110:277989. https://doi.org/10.1016/j.bpj.2016.03.023.
23. West KA, Castillo SS, Dennis PA. Activation of the PI3K/Akt pathway and chemotherapeutic resistance. Drug Resist Update. 2002;5:234-48. https:// doi.org/10.1016/s1368-7646(02)00120-6.

24. Li Z, Ju X, Silveira PA, Abadir E, Hsu WH, Hart DNJ, et al. CD83: activation marker for antigen presenting cells and its therapeutic potential. Front Immunol. 2019;10:1312. https://doi.org/10.3389/fimmu.2019.01312.

25. Liu Z, Shimada M, Richards JS. The involvement of the Toll-like receptor family in ovulation. J Assist Reprod Genet. 2008;25:223-8. https://doi.org/ 10.1007/s10815-008-9219-0.

26. Talebi R, Ahmadi A, Afraz F, Sarry J, Plisson-Petit F, Genet C, et al. Transcriptome analysis of ovine granulosa cells reveals differences between small antral follicles collected during the follicular and luteal phases. Theriogenology. 2018;108:103-17. https://doi.org/10.1016/j.theriogenology.2017. 11.027

27. Saadeldin IM, Tukur HA, Aljumaah RS, Sindi RA. Rocking the boat: the decisive roles of rRho kinases during oocyte, blastocyst, and stem cell development. Front Cell Dev Biol. 2020;8:616-762. https://doi.org/10. 3389/fcell.2020.616762.

28. Lamalice L, Le Boeuf F, Huot J. Endothelial cell migration during angiogenesis. Circ Res. 2007;100:782-94. https://doi.org/10.1161/01.RES.00002 59593.07661.1e.

29. Shimizu T, Berisha B, Schams D, Miyamoto A. Expression of angiopoietin (ANPT)-1, ANPT-2 and their receptors in dominant follicles during periovulatory period in GnRH-treated cow. Reprod Domest Anim. 2007:42:221-4. https://doi.org/10.1111/j.1439-0531.2006.00748.x.

30. Berkholtz CB, Shea LD, Woodruff TK. Extracellular matrix functions in follicle maturation. Semin Reprod Med. 2006;24:262-9. https://doi.org/10. 1055/s-2006-948555.

31. Qiu H, Zhu B, Ni S. Identification of genes associated with primary open-angle glaucoma by bioinformatics approach. Int Ophthalmol. 2018:38:19-28. https://doi.org/10.1007/s10792-017-0704-2.

32. Welt CK. Regulation and function of inhibins in the normal menstrual cycle. Semin Reprod Med. 2004;22:187-93. https://doi.org/10. 1055/s-2004-831894.

33. Silva JRV, Hurk Rvd, Tol HTAv, Roelen BAJ, Figueiredo JR. Gene expression and protein localisation for activin-A, follistatin and activin receptors in goat ovaries. J Endocrinol. 2004;183(2):405-15. https://doi.org/10.1677/ joe.1.05756.

34. Muttukrishna S, Tannetta D, Groome N, Sargent I. Activin and follistatin in female reproduction. Mol Cell Endocrinol. 2004;225:45-56. https://doi. org/10.1016/j.mce.2004.02.012.

35. Schneider MR, Wolf E. The epidermal growth factor receptor and its ligands in female reproduction: insights from rodent models. Cytokine Growth Factor Rev. 2008;19:173-81. https://doi.org/10.1016/j.cytogfr. 2008.01.003.

36. Prochazka R, Blaha M, Nemcová L. Significance of epidermal growth factor receptor signaling for acquisition of meiotic and developmental competence in mammalian oocytes. Biol Reprod. 2017;97:537-49. https://doi. org/10.1093/biolre/iox112.

37. Richani D, Gilchrist RB. The epidermal growth factor network: role in oocyte growth, maturation and developmental competence. Hum Reprod Update. 2018;24:1-14. https://doi.org/10.1093/humupd/dmx029.

38. Prevot V, Lomniczi A, Corfas G, Ojeda SR. ErbB-1 and erbB-4 receptors act in concert to facilitate female sexual development and mature reproductive function. Endocrinology. 2005;146:1465-72. https://doi.org/10.1210/ en.2004-1146.

39. Bowden M, Drummond AE, Salamonsen LA, Findlay JK, Nie G. Evolutionary conservation of mammalian HTRA3 and its developmental regulation in the rat ovary. J Exp Zool B Mol Dev Evol. 2009;312:701-13. https://doi. org/10.1002/jez.b.21288.

40. Bowden MA, Drummond AE, Fuller PJ, Salamonsen LA, Findlay JK, Nie G. High-temperature requirement factor A3 (Htra3): a novel serine protease and its potential role in ovarian function and ovarian cancers. Mol Cell Endocrinol. 2010;327:13-8. https://doi.org/10.1016/j.mce.2010.06.001.

41. Tang ZR, Zhang R, Lian ZX, Deng SL. Estrogen-receptor expression and function in female reproductive Disease. Cells. 2019;8(10):1123. https:// doi.org/10.3390/cells8101123.

42. Fang $L$, Chang HM, Cheng JC, Leung PC, Sun YP. TGF-beta1 induces COX-2 expression and PGE2 production in human granulosa cells through Smad signaling pathways. J Clin Endocrinol Metab. 2014;99:E1217-1226. https:// doi.org/10.1210/jc.2013-4100. 
43. Yoshioka S, Ochsner S, Russell D, Ujioka TF S, Richards J, Espey L. Expression of tumor necrosis factor-stimulated gene- 6 in the rat ovary in response to an ovulatory dose of gonadotropin. Endocrinol Metab Clin North Am. 2000;141:4114-9. https://doi.org/10.1210/en.141.11.4114.

44. Fulop C, Szanto S, Mukhopadhyay D, Bardos T, Kamath RV, Rugg MS, et al. Impaired cumulus mucification and female sterility in tumor necrosis factor-induced protein-6 deficient mice. Development. 2003;130:225361. https://doi.org/10.1242/dev.00422.

45. Murakami M, Kudo I. Recent advances in molecular biology and physiology of the prostaglandin E-2-biosynthetic pathway. Prog Lipid Res. 2004;43:3-35. https://doi.org/10.1016/s0163-7827(03)00037-7.

46. Gonzalez-Martinez D, De Mees C, Douhard Q, Szpirer C, Bakker J. Absence of gonadotropin-releasing hormone 1 and kiss1 activation in alphafetoprotein knockout mice: prenatal estrogens defeminize the potential to show preovulatory luteinizing hormone surges. Endocrinology. 2008;149:2333-40. https://doi.org/10.1210/en.2007-1422.

47. Zhai B, Liu H, Li X, Dai L, Gao Y, Li C, et al. BMP15 prevents cumulus cell apoptosis through CCL2 and FBN1 in porcine ovaries. Cell Physiol Biochem. 2013;32:264-78. https://doi.org/10.1159/000354435.

48. Lin YC, Liu CY, Kannagi R, Yang RB. Inhibition of endothelial SCUBE2 (Signal Peptide-CUB-EGF Domain-Containing Protein 2), a novel VEGFR2 (Vascular Endothelial Growth Factor Receptor 2) coreceptor, suppresses tumor angiogenesis. Arterioscler Thromb Vasc Biol. 2018;38:1202-15. https://doi.org/10.1161/atvbaha.117.310506.

49. Maisonpierre PC, Suri C, Jones PF, Bartunkova S, Wiegand S, Radziejewsk C, et al. Angiopoietin-2, a natural antagonist for Tie2 that disrupts in vivo angiogenesis. Science. 1997;277:55-60. https://doi.org/10.1126/science. 277.5322.55.

50. Parborell F, Abramovich D, Irusta G, Tesone M. Angiopoietin 1 reduces rat follicular atresia mediated by apoptosis through the PI3K/Akt pathway. Mol Cell Endocrinol. 2011;343:79-87. https://doi.org/10.1016/j.mce.2011. 06.009 .

51. Benezra R, Rafii S, Lyden D. The Id proteins and angiogenesis. Oncogene. 2001;20:8334-41. https://doi.org/10.1038/sj.onc.1205160.

52. Fraser HM. Regulation of the ovarian follicular vasculature. Reprod Biol Endocrinol. 2006;4:18. https://doi.org/10.1186/1477-7827-4-18.

53. Furuhashi M, Saitoh S, Shimamoto K, Miura T. Fatty Acid-Binding Protein 4 (FABP4): pathophysiological insights and potent clinical biomarker of metabolic and cardiovascular diseases. Clin Med Insights Cardiol. 2014;8:23-33. https://doi.org/10.4137/cmc.s17067.

54. Van Wezel IL, Dharmarajan AM, Lavranos TC, Rodgers RJ. Evidence for alternative pathways of granulosa cell death in healthy and slightly atretic bovine antral follicles. Endocrinology. 1999;140:2602-12. https://doi.org/ 10.1210/endo.140.6.6758.

55. Nourani MR, Owada Y, Kitanaka N, Sakagami H, Hoshi H, Iwasa H, et al. Occurrence of immunoreactivity for adipocyte-type fatty acid binding protein in degenerating granulosa cells in atretic antral follicles of mouse ovary. J Mol Histol. 2005;36:491-7. https://doi.org/10.1007/ s10735-006-9024-y.

56. Wang J, Tang J, Wang B, Song J, Liu J, Wei Z, et al. FABP4: a novel candidate gene for polycystic ovary syndrome. Endocrine. 2009;36:392-6. https://doi.org/10.1007/s12020-009-9228-5.

57. De Santis ML, Hammamieh R, Das R, Jett M. Adipocyte-fatty acid binding protein induces apoptosis in DU145 prostate cancer cells. J Exp Ther Oncol. 2004:4:91-100.

58. Song H, Lim H, Paria BC, Matsumoto H, Swift LL, Morrow J, et al. Cytosolic phospholipase A(2)alpha deficiency is crucial for "on-time" embryo implantation that directs subsequent development. Development. 2002;129:2879-89.

59. Boruszewska D, Kowalczyk-Zieba I, Suwik K, Staszkiewicz-Chodor J, Jaworska J, Lukaszuk K, et al. Prostaglandin E(2) affects in vitro maturation of bovine oocytes. Reprod Biol Endocrinol. 2020;18:40. https://doi.org/10. 1186/s12958-020-00598-9.

60. Kurusu S, Sapirstein A, Bonventre JV. Group IVA phospholipase A(2) optimizes ovulation and fertilization in rodents through induction of and metabolic coupling with prostaglandin endoperoxide synthase 2. FASEB J. 2012;26:3800-10. https://doi.org/10.1096/f.12-203968.

61. Sapieha P, Stahl A, Chen J, Seaward MR, Willett KL, Krah NM, et al. 5-Lipoxygenase metabolite 4-HDHA is a mediator of the antiangiogenic effect of omega-3 polyunsaturated fatty acids. Sci Transl Med. 2011;3(69):69ra12. https://doi.org/10.1126/scitranslmed.3001571.
62. Llavanera M, Mateo-Otero Y, Bonet S, Barranco I, Fernandez-Fuertes $B$, Yeste $M$. The triple role of glutathione S-transferases in mammalian male fertility. Cell Mol Life Sci. 2019. https://doi.org/10.1007/ s00018-019-03405-w.

63. Accili D, Arden KC. FoxOs at the crossroads of cellular metabolism, differentiation, and transformation. Cell. 2004;117:421-6. https://doi.org/10. 1016/s0092-8674(04)00452-0.

64. Daitoku H, Fukamizu A. FOXO transcription factors in the regulatory networks of longevity. J Biochem. 2007;141:769-74. https://doi.org/10.1093/ $\mathrm{jb} / \mathrm{mvm} 104$.

65. Kim DH, Zhang T, Lee S, Dong HH. FoxO6 in glucose metabolism (FoxO6). J Diabetes. 2013;5:233-40. https://doi.org/10.1111/1753-0407.12027.

66. Li Q, Tang H, Hu F, Qin C. Silencing of FOXO6 inhibits the proliferation, invasion, and glycolysis in colorectal cancer cells. J Cell Biochem. 2019;120:3853-60. https://doi.org/10.1002/jcb.27667.

67. Tian H, Liu K, Zhang Y, Qi Q, Wang C, Guan H, et al. Adult follicular fluid supplementation during in vitro maturation improves the developmental competence of prepubertal lamb oocytes. Theriogenology. 2019;130:157-62. https://doi.org/10.1016/j.theriogenology.2019.03.009.

\section{Publisher's Note}

Springer Nature remains neutral with regard to jurisdictional claims in published maps and institutional affiliations.

Ready to submit your research? Choose BMC and benefit from:

- fast, convenient online submission

- thorough peer review by experienced researchers in your field

- rapid publication on acceptance

- support for research data, including large and complex data types

- gold Open Access which fosters wider collaboration and increased citations

- maximum visibility for your research: over $100 \mathrm{M}$ website views per year

At BMC, research is always in progress.

Learn more biomedcentral.com/submissions 